\author{
Е.Е. Жуланов, В.П. Постников, К.А. Шишкина
}

\author{
СОВЕРШЕНСТВОВАНИЕ МЕХАНИЗМА \\ НОРМИРОВАНИЯ ЧИСЛЕННОСТИ ПЕРСОНАЛА \\ НЕФТЕПЕРЕРАБАТЫВАЮЩЕГО ПРЕДПРИЯТИЯ \\ НА ОСНОВЕ МЕТОДОВ РЕГРЕССИОННОГО АНАЛИЗА
}

\begin{abstract}
Предложен инновационный подход к нормированию численности персонала на нефтеперерабатывающем предприятии. Определение оптимального числа работников позволит снизить существенную часть затрат, что в условиях нестабильности конъюнктуры рынка положительно воздействует на эфффективность деятельности предприятия в целом. Существующие методы определения норм численности персонала, традиционно применяемые на предприятиях, не учитывают влияния профессионального опыта на трудозатраты. В основе нового подхода лежит эконометрическое моделирование, которое позволяет выявить уменьшение или увеличение нормы трудозатрат на выполнение одной операции в зависимости от количества ее повторений. Эконометрически скорректированные нормы трудоемкости позволят гибко переоценивать изменение трудовых норм и определять более точно необходимое предприятию количество трудовых ресурсов для выполнения конкретного объема работ. Для подтверждения гипотезы был проведен анализ по 10 однотипным работам на основе данных за 12 месяцев. Были построены модели, отражающие влияние профессиональных навыков на удельные трудозатраты для работ с наиболее сильной связью между параметром и фактором: участие в организации разработки планов осмотров и профилактических ремонтов оборудования, контроль физических объемов, выполненных подрядными организациями работ по административно-бытовым и складским объектам и подготовка данных о несоответствии качества вспомогательных материалов и оборудования требованиям технической документации и стандартов. На основе сравнения скорректированных норм трудозатрат регрессионного моделирования и фактически действующих норм на предприятии можно сделать вывод о том, что применение инновационного подхода уточняет значение норм трудозатрат, исходя из которых также будет уточнен размер численности работников предприятия.

Ключевые слова: нормирование численности персонала, эконометрическое моделирование, регрессионный подход, трудозатраты, нормы труда.
\end{abstract}

В условиях нестабильности рыночной конъюнктуры и темпа развития экономики предприятий для эффективного функционирования каждого из них необходимо рациональное управление своими издержками, в том числе затра-

(С) Жуланов Е.Е., Постников В.П., Шишкина К.А., 2020

Жуланов Евгений Евгеньевич - д-р экон. наук, профессор кафедры экономики и управления промышленным производством ФГБОУ ВО «Пермский национальный исследовательский политехнический университет», e-mail: zeepstu@yandex.ru.

Постников Владимир Павлович - канд. экон. наук, доцент кафедры экономики и управления промышленным производством, ФГБОУ ВО «Пермский национальный исследовательский политехнический университет», e-mail: v.p.o.s.t.v@mail.ru.

Шишкина Ксения Андреевна - магистрант кафредры экономики и управления промышленным производством ФГБОУ ВО «Пермский национальный исследовательский политехнический университет», e-mail: shishckina.xenia2014@yandex.ru. 
тами на трудовые ресурсы [1]. Задача определения оптимального числа работников, необходимого для выполнения планируемого объема, выходит на первый план для предприятий различных отраслей, так как ее решение позволит снизить существенную часть затрат, включаемую в себестоимость готовой продукции за счет экономии на фонде оплаты труда и страховых взносах [2].

Однако существующие методы определения норм численности персонала, традиционно применяемые на предприятиях: по нормам трудоемкости, по нормам выработки, по нормам обслуживания и по местам обслуживания, обладают одним общим недостатком - они не учитывают влияние профессионального опыта на трудозатраты [3-5]. Между тем этот фактор оказывает значительное влияние на уровень производительности труда. При наличии профессионального опыта временные трудозатраты минимальны и, наоборот, как показали исследования, проведенные на одном из предприятий нефтеперерабатывающей ${ }^{1}$ промышленности, при отсутствии опыта их уровень поможет трехкратно превосходить минимальную величину.

Поскольку профессиональный опыт формируется в результате многократного повторения производственных операций, то возникает необходимость в применении инновационного подхода к нормированию труда, развивающего вышеуказанные методы расчета численности персонала. В основу такого подхода может быть положено эконометрическое моделирование, позволяющее определять изменение нормы трудозатрат на выполнение одной производственной операции в зависимости от количества раз выполнения таких же операции за определенный период [6]. Такое моделирование позволит гибко переоценивать изменение трудовых норм при увеличении или сокращении производственной программы предприятия и сделает более точным нормирование численности персонала, так как при ее расчете с применением вышеуказанных методов будут использованы эконометрически скорректированные величины норм трудоемкости, выработки или обслуживания.

Для подтверждения этой гипотезы было проведено исследование, целью которого послужило построение модели прогнозирования изменения трудозатрат на единицу работы в зависимости от частоты ее повторения, т.е. отражающей влияние профессиональных навыков на удельные трудозатраты.

Объектом исследования при этом явилось нефтеперерабатывающее предприятие. Для достижения заявленной цели были поставлены и последовательно решены следующие задачи:

1) провести исследование норм трудозатрат специалистов отдела главного механика и выделить круг однотипных работ, выполняемых разными специалистами с разной частотой повторения за год.

${ }^{1}$ Конкретное наименование не называется в связи с необходимостью соблюдения требований Федерального закона РФ «О коммерческой тайне» № 98-ФЗ от 29.07.2004 г. 
2) на основе собранной информации оценить корреляционную тесноту связи между трудозатратами специалистов на единицу работы и количеством раз ее повторений;

3) для работ, по которым наблюдается наиболее сильная связь, построить уравнение регрессии, прогнозирующее величину трудозатрат на выполнение работы при изменении количества раз ее повторения, и оценить качество модели.

Анализ проводился по 10 однотипным работам, представленным в табл. 1. Для оценки тесноты связи между переменными $X$ и $Y$ ( $Y$ - трудозатраты на единицу работы; и $X$ - количество раз повторения работ) был проведен корреляционный анализ по данным за 12 месяцев, результаты которого представлены в этой же таблице.

Таблица 1

Результаты корреляционного анализа трудозатрат на единицу работы и количеством ее повторений

\begin{tabular}{|c|l|c|c|c|}
\hline $\begin{array}{c}\text { № } \\
\text { п/п }\end{array}$ & \multicolumn{1}{|c|}{ Вид работы } & $\begin{array}{c}\text { Степень } \\
\text { влияния }\end{array}$ & Тип связи & $\begin{array}{c}\text { Характер } \\
\text { связи }\end{array}$ \\
\hline 1 & $\begin{array}{l}\text { Участие в организации разработки планов } \\
\text { графика) осмотров, испытаний и профи- } \\
\text { лактических ремонтов оборудования }\end{array}$ & $-0,78$ & Сильная & Обратная \\
\hline 2 & $\begin{array}{l}\text { Подготовка данных о несоответствии ка- } \\
\text { чества вспомогательных материалов и } \\
\text { оборудования требованиям технической } \\
\text { документации и стандартов }\end{array}$ & $-0,75$ & Сильная & Обратная \\
\hline 3 & $\begin{array}{l}\text { Контроль физических объемов выполнен- } \\
\text { ных подрядными организациями работ по } \\
\text { административно-бытовым и складским } \\
\text { зданиям, оборудованию }\end{array}$ & $-0,74$ & Сильная & Обратная \\
\hline 4 & $\begin{array}{l}\text { Разработка рабочих инструкций по техни- } \\
\text { ческому обслуживанию и ремонту объек- } \\
\text { тов }\end{array}$ & $-0,49$ & Слабая & Обратная \\
\hline 5 & $\begin{array}{l}\text { Организация работы по контролю качест- } \\
\text { ва монтажа, качества ремонтных работ по } \\
\text { объектам }\end{array}$ & $-0,45$ & Слабая & Обратная \\
\hline 6 & $\begin{array}{l}\text { Прием от механиков установок заявок на } \\
\text { ремонт и изготовление запасных частей }\end{array}$ & $-0,36$ & Слабая & Обратная \\
\hline 7 & $\begin{array}{l}\text { Организация учета всего установленного } \\
\text { на производстве оборудования, изменений } \\
\text { условий его работы }\end{array}$ & $-0,3$ & Слабая & Обратная \\
\hline 8 & $\begin{array}{l}\text { Участие в составлении дефектных ведо- } \\
\text { мостей на оборудование }\end{array}$ & $-0,28$ & Слабая & Обратная \\
\hline 9 & Участие в расследовании причин аварий \\
\hline 10 & $\begin{array}{l}\text { Подготовка и сопровождение тендерной } \\
\text { документации по ремонтам }\end{array}$ & $-0,09$ & Слабая & Обратная \\
\hline
\end{tabular}


По данным таблицы можно сделать вывод, что наиболее сильная взаимосвязь между переменными наблюдалась по следующим видам работ:

1) участие в организации разработки планов (графика) осмотров, испытаний и профилактических ремонтов оборудования $(r=-0,78)$;

2) контроль физических объемов, выполненных подрядными организациями работ по административно-бытовым и складским зданиям, оборудованию $(r=-0,74)$;

3) подготовка данных о несоответствии качества вспомогательных материалов и оборудования требованиям технической документации и стандартов $(r=-0,75)$.

Величина коэффициента корреляции у данных видов работ находится в диапазоне от 0,7 до 0,9 , что говорит о сильной связи между трудозатратами на единицу работы специалиста и количеством повторений работы [7]. Отрицательная величина коэффициента указывает на обратную зависимость между показателем и фактором, т.е. с каждым повторением работы специалисту требуется меньше трудозатрат на ее выполнение [8].

Слабая связь между показателем и фактором прослеживалась по следующим видам работ:

1) организация учета всего установленного на производстве оборудования и изменений условий его работы $(r=-0,3)$;

2) организация работы по контролю качества монтажа и качества ремонтных работ по объектам $(r=-0,45)$;

3) разработка рабочих инструкций по техническому обслуживанию и ремонту объектов $(r=-0,49)$;

4) прием от механиков установок заявок на ремонт и изготовление запасных частей $(r=-0,36)$;

5) участие в составлении дефектных ведомостей на оборудование $(r=-0,28)$;

6) участие в расследовании причин аварий $(r=0,24)$;

7) подготовка и сопровождение тендерной документации по ремонтам оборудования $(r=-0,09)$.

О слабой связи показателя и фактора говорит диапазон коэффициента корреляции от 0,3 до 0,5 [9]. Также у вышеперечисленных работ наблюдается обратная зависимость между трудозатратами на единицу работы специалиста и количеством повторений работы. Коэффициент корреляции ниже 0,3 говорит о практическом отсутствии взаимосвязи между трудозатратами на единицу работы специалиста и количеством повторений работы [10].

У большинства видов работ не наблюдается сильной связи между трудозатратами на единицу работы и количеством ее повторений, так как, возможно, данные виды работ требуют индивидуального подхода и в силу этого не наблюдается снижение трудозатрат при их повторении. 
Далее для работ с наиболее сильной связью были построены уравнения регрессии, которые отражают зависимость переменной $Y$ от переменной $X$.

1. Для работы «Участие в организации разработки планов (графика) осмотров, испытаний и профилактических ремонтов оборудования» регрессионная модель имеет вид

$$
y_{i}=50,11-0,65 \cdot x_{i}
$$

где $y$ - трудозатраты на одно участие в организации разработки плана (графика) осмотра, испытания и профилактического ремонта единицы оборудования, часы на ед. работ; $x$ - количество раз составления указанного плана (графика), ед.

Уравнение (1) показывает зависимость нормы трудозатрат на единицу работы по разработке плана (графика) осмотра, испытания и профилактического ремонта оборудования в зависимости от количества объектов, запланированных к обслуживанию за год. Коэффициент детерминации регрессионной модели $R^{2}$ составляет 0,61 , что говорит о хорошем качестве построенной модели, поскольку она с точностью 61 \% прогнозирует размер будущих фактических норм трудозатрат [11].

2. Для работы «Контроль физических объемов выполненных подрядными организациями работ по административно-бытовым и складским зданиям, оборудованию» модель имеет следующие параметры:

$$
y_{i}=3,46-0,01 \cdot x_{i}
$$

где $y$ - норма трудозатрат на выполнение одной операции по контролю физических объемов работ, выполненных подрядными организациями на одном объекте (административно-бытовому или складскому зданию, технологическому объекту), часы на ед. работ; $x$ - количество раз повторения контролирующих операций, ед.

Уравнение (2) показывает зависимость нормы трудозатрат на один контроль за выполнением ремонтных работ подрядными организациями на одном объекте в зависимости от количества запланированных контролирующих операций за год. Полученная регрессионная модель (2) характеризуется коэффициентом детерминации $R^{2}$, равным 0,54 , который отражает приемлемое качество построенной модели и позволяет с точностью в 54 \% предсказать изменение нормы трудозатрат на выполнение контрольной операции [12].

3. Для работы «Подготовка данных о несоответствии качества вспомогательных материалов и оборудования требованиям технической документации и стандартов» была получена модель вида

$$
y_{i}=1,42-0,02 \cdot x_{i}
$$

где $y$ - трудозатраты на однократную подготовку данных о несоответствии качества вспомогательных материалов или оборудования требованиям техни- 
ческой документации и стандартов, часы на ед. работ; $x$ - количество раз повторения подготовки данных о несоответствии за год, ед.

Уравнение (3) показывает зависимость нормы трудозатрат на одну подготовку данных о несоответствии качества вспомогательных материалов или оборудования требованиям технической документации и стандартов от количества раз выявленных несоответствий, оцениваемых по факту предыдущего года. Коэффициент детерминации $R^{2}$ для регрессионной модели (3) составляет 0,56 , что говорит о хорошем качестве построенной модели, так как она на 56 \% точно прогнозирует норму трудозатрат при подготовке данных о несоответствии качества [13].

Оценка качества регрессионных моделей для видов работ с наиболее сильной связью (1)-(3) между показателем и фактором представлена в табл. 2.

Таблица 2

Оценка качества регрессионных моделей

\begin{tabular}{|l|c|c|c|}
\hline \multicolumn{1}{|c|}{ Вид работы } & Уравнение & $r$ & $R^{2}$ \\
\hline $\begin{array}{l}\text { Участие в организации разработки планов } \\
\text { (графика) осмотров, испытаний и профилакти- } \\
\text { ческих ремонтов оборудования }\end{array}$ & $y_{i}=50,11-0,65 x_{i}$ & $-0,78$ & 0,61 \\
\hline $\begin{array}{l}\text { Контроль физических объемов выполненных } \\
\text { подрядными организациями работ по админи- } \\
\text { стративно-бытовым и складским зданиям, обо- } \\
\text { рудованию }\end{array}$ & $y_{i}=3,46-0,01 x_{i}$ & $-0,74$ & 0,54 \\
\hline $\begin{array}{l}\text { Подготовка данных о несоответствии качества } \\
\text { вспомогательных материалов и оборудования } \\
\text { требованиям технической документации и } \\
\text { стандартов }\end{array}$ & $y_{i}=1,42-0,02 x_{i}$ & $-0,75$ & 0,56 \\
\hline
\end{tabular}

На основе оценки качества моделей можно сделать несколько выводов. Расчеты показали, что наиболее тесную связь между трудозатратами на единицу работы и количеством ее повторений имеет работа по участию в организации разработки планов (графиков) осмотров, испытаний и профилактических ремонтов оборудования, поскольку в этом случае корреляция составляет $-0,78$, что свидетельствует о сильном влиянии фактора на объясняемую переменную [14]. С работой по контролю физических объемов выполненных подрядными организациями работ по административно-бытовым и складским зданиям, оборудованию взаимосвязь составила $-0,74$, а с работой по подготовке данных о несоответствии качества вспомогательных материалов и оборудования требованиям технической документации и стандартов $-0,75$. Таким образом, все показатели оказывают обратное и заметное воздействие на объем трудозатрат [15]. В целом общая оценка качества моделей отразила их устойчивость и приемлемость использования, поскольку во всех случаях наблюдается сильная связь между параметром и фактором, а коэффициент детерминации моделей составляет более 50 \% [16]. 
Также был проведен корреляционный анализ для оценки тесноты связи между трудозатратами комплекса работ, который выполняет конкретный специалист-механик, и количеством повторений каждой его работы (табл. 3).

Таблица 3

\section{Результат корреляционного анализа трудозатрат}

между комплексом работ, который выполняет конкретный специалист, и количеством повторений каждой работы

\begin{tabular}{|c|c|c|c|}
\hline $\begin{array}{c}\text { Номер специалиста- } \\
\text { механика }\end{array}$ & $\begin{array}{c}\text { Степень } \\
\text { влияния }\end{array}$ & Тип связи & Характер связи \\
\hline 1 & 0,83 & Сильная & Прямая \\
\hline 2 & $-0,58$ & Заметная & Обратная \\
\hline 3 & $-0,53$ & Заметная & Обратная \\
\hline 4 & $-0,50$ & Заметная & Обратная \\
\hline 5 & $-0,47$ & Слабая & Обратная \\
\hline 6 & $-0,47$ & Слабая & Обратная \\
\hline 7 & $-0,47$ & Слабая & Обратная \\
\hline 8 & $-0,46$ & Слабая & Обратная \\
\hline 9 & $-0,44$ & Слабая & Обратная \\
\hline 10 & $-0,43$ & Слабая & Обратная \\
\hline 11 & $-0,43$ & Слабая & Обратная \\
\hline 12 & $-0,37$ & Слабая & Обратная \\
\hline 13 & 0,25 & Практически отсутствует & Прямая \\
\hline 14 & $-0,16$ & Практически отсутствует & Обратная \\
\hline
\end{tabular}

По данным таблицы можно сделать следующие выводы:

1) только у 1 специалиста из 14 наблюдается сильная связь и прямая зависимость между показателем нормы трудозатрат $(Y)$ и количеством раз повторения работ $(X)$, так как коэффициент корреляции равен 0,83 , т.е. имеется прямая зависимость и с каждым повторением работы специалисту требуется больше трудозатрат на ее выполнение [11];

2) заметная связь между показателем нормы трудозатрат и количеством раз повторения работ прослеживается у 3 специалистов из 14, так как диапазон коэффициента корреляции от 0,5 до 0,7, а поскольку значение коэффициентов отрицательное, то можно говорить об обратной зависимости между этими показателями [18];

4) слабая связь $(r=0,3 \ldots 0,5)$ и обратная зависимость между показателем нормы трудозатрат и количеством раз повторения работы выявлена у 8 специалистов из 14;

5) практически отсутствует связь между показателем нормы трудозатрат и количеством раз повторения работы наблюдается у 2 работников из 14, так как коэффициент корреляции ниже 0,3 [18]. 
Отсутствие у большинства специалистов сильной связи между нормами трудозатрат на единицу работы $(Y)$ и количеством раз их повторений $(X)$ обусловлено тем, что выполнение работ требует индивидуального подхода.

Для специалиста № 1 с сильной связью между $X$ и $Y$ также было построено регрессионное уравнение, которое имеет вид

$$
y_{i}=282,71-90,69 \cdot x_{i},
$$

где $y$ - результирующий показатель нормы трудозатрат на единицу работы по внесению данных в SAP R/3, подготовку и сопровождение тендерной документации на ремонт оборудования и составление конкурсных карт, часы/1 нат. ед. работ; $x$ - влияющий фактор количества раз повторения выполнения работы.

Уравнение (4) показывает норму трудозатрат на единицу работы специалиста № 1 по внесению данных в SAP R/3, подготовку и сопровождение тендерной документации, и составление конкурсных карт на один ремонт оборудования в зависимости от количества ремонтов. Коэффициент детерминации, рассчитанный для модели (4) $-R^{2}$ равен 0,68 , т.е. данное уравнение регрессии позволяет с точностью в 68 \% получить фактическую будущую норму трудозатрат, исходя из намеченной программы ремонтов в планируемом году. Оценка модели также показала ее надежность, как и в других случаях [19].

Таким образом, сопоставляя средние нормы трудозатрат, применяемые на нефтеперерабатывающем предприятии, и нормы, полученные по регрессионной модели (табл. 4), можно сделать вывод о том, что применение регрессионного моделирования уточняет значение этих норм, исходя из которых также будет уточнен размер численности работников нефтеперерабатывающего предприятия вышеуказанными методами.

Таблица 4

Сравнительный анализ норм трудозатрат на нефтеперерабатывающем предприятии и полученных по регрессионным моделям

\begin{tabular}{|c|c|c|c|c|c|}
\hline \multirow[t]{2}{*}{$\begin{array}{l}\text { № } \\
\Pi / \Pi\end{array}$} & \multirow[b]{2}{*}{ Вид работы } & \multicolumn{2}{|c|}{\begin{tabular}{|c|} 
Норма трудозатрат, часы/1 нат. \\
ед. работ \\
\end{tabular}} & \multicolumn{2}{|c|}{ Отклонение } \\
\hline & & $\begin{array}{l}\text { действующая } \\
\text { на предприятии }\end{array}$ & $\begin{array}{c}\text { рассчитанная } \\
\text { по моделям } \\
\text { регрессии }\end{array}$ & $\begin{array}{c}\text { абсо- } \\
\text { лютное }\end{array}$ & $\begin{array}{c}\text { относи- } \\
\text { тельное, \% }\end{array}$ \\
\hline 1 & $\begin{array}{l}\text { Участие в организации раз- } \\
\text { работки планов (графика) } \\
\text { осмотров, испытаний и про- } \\
\text { филактических ремонтов } \\
\text { оборудования }\end{array}$ & 56,31 & 16,4 & $-39,91$ & $-70,88$ \\
\hline 2 & $\begin{array}{l}\text { Подготовка данных о несо- } \\
\text { ответствии качества вспомо- } \\
\text { гательных материалов и } \\
\text { оборудования требованиям } \\
\text { технической документации } \\
\text { и стандартов }\end{array}$ & 2 & 1,14 & $-0,86$ & -43 \\
\hline
\end{tabular}


Окончание табл. 4

\begin{tabular}{|c|l|c|c|c|c|}
\hline \multirow{2}{*}{$\begin{array}{c}\text { № } \\
\text { n/п }\end{array}$} & \multicolumn{1}{|c|}{ Вид работы } & $\begin{array}{r}\text { Норма трудозатрат, часы/1 нат. } \\
\text { ед. работ }\end{array}$ & \multicolumn{2}{|c|}{ Отклонение } \\
\cline { 3 - 6 } & $\begin{array}{c}\text { действующая } \\
\text { на предприятии }\end{array}$ & $\begin{array}{c}\text { рассчитанная } \\
\text { по моделям } \\
\text { регрессии }\end{array}$ & $\begin{array}{c}\text { абсо- } \\
\text { лютное }\end{array}$ & $\begin{array}{c}\text { отнольль- } \\
\text { телое, \% }\end{array}$ \\
\hline 3 & $\begin{array}{l}\text { Контроль физических объе- } \\
\text { мов выполненных подряд- } \\
\text { ными организациями работ } \\
\text { по административно- } \\
\text { бытовым и складским зда- } \\
\text { ниям, оборудованию }\end{array}$ & 3,24 & 1,85 & $-1,39$ & $-42,9$ \\
\hline $\begin{array}{l}\text { Внесение данных в SАР R/3, } \\
\text { подготовка и сопровождение } \\
\text { тендерной документации по } \\
\text { ремонтам, составление кон- } \\
\text { курсных карт }\end{array}$ & 206,4 & 80,03 & $-126,37$ & $-61,23$ \\
\hline
\end{tabular}

В статье был предложен новый подход к определению норм труда на основе эконометрического моделирования. Исследование показало, что данный подход позволяет определить изменение трудозатрат на выполнение одной операции в зависимости от количества ее повторений. В результате сравнительного анализа фактических норм трудозатрат и полученных по регрессионным моделям можно сделать вывод, что внедрение предложенного инструмента позволит оптимизировать часть издержек нефтедобывающего предприятия.

\section{Список литературы}

1. Мумладзе Р.Г., Гужина Г.Н. Экономика и социология труда : учебник для студентов высших учебных заведений. - М.: КНОРУС, 2019. - 320 с.

2. Язенко Е.И. Применение различных методик в определении оптимальной численности персонала предприятия // Российское предпринимательство. - 2012. - № 17. - С. 79-84.

3. Экономика, организация и управление промышленным предприятием: учебник для вузов / Е.Д. Коршунова [и др.]. - М.: КУРС, ИНФРА-М, 2019. - 272 с.

4. Павленко А.П. Определение необходимой численности персонала организаций // Нормирование и оплата труда в промышленности. - 2016. - № 5. C. $17-30$.

5. Шарашкин А.Н., Никитина Л.М. Разработка и обоснование методики определения оптимальной численности персонала // Дизайн. Материалы. Технология. - 2012. - № 4. - С. 136-141.

6. Балаш О.С. Эконометрическое моделирование пространственных взаимодействий // Известия Саратовского университета. Экономика. Управление. Право. - 2012. - № 3. - С. 30-35. 
7. Балаш О.С., Харламов А.В. Эконометрическое моделирование пространственных данных: моногр. - Саратов: Научная книга, 2010. - 112 с.

8. Эконометрика: учеб. для вузов / К.В. Балдин [и др.]. - М.: Дашков и К, 2017. -564 c.

9. Темукуева Ж.Х. Корреляционно-регрессионный анализ как индикатор отбора показателей при проведении факторного экономического анализа // Проблемы современной науки и образования. - 2016. - № 19. - С. 67-69.

10. Прозорова Ю.Ю., Хомяченко А.А. Использование корреляционнорегрессионного анализа в процессе анализа эффективности использования трудовых ресурсов предприятия // Таврический научный обозреватель 2017. - № 20. - С. 32-35.

11. Бараз В.Р. Корреляционно-регрессионный анализ связи показателей коммерческой деятельности с использованием программы Excel: учеб. пособие. - Екатеринбург: Изд-во УГТУ-УПИ, 2005. - 102 с.

12. Красильников Д.Е. Алгоритм вычисления коэффициента выборочной детерминации в MS-Excel [Электронный ресурс] // Труды НГТУ им. Р.Е. Алексеева. - 2016. - URL: https://cyberleninka.ru/article/n/algoritm-vychisleniyakoeffitsienta-vyborochnoy-determinatsii-v-ms-excel (дата обращения: 04.05.2020).

13. Панорама экономической мысли конца XX столетия: в 2 т. / под ред. Д. Гринэуэй, М. Блини, И. Стюарта. - Т. 2. - СПб.: Экон. шк., 2002.

14. Эконометрика: учеб. для бакалавр. и магистр. / И.И. Елисеева [и др.]. М.: Юрайт, 2017. - 449 с.

15. Андреева Н.В., Червякова М.Ю. Разработка методики прогнозирования с использованием корреляционно-регрессионного анализа // Экономический анализ: теория и практика. - 2013. - № 37. - С. 38-45.

16. Колемаев В.А. Эконометрика: учеб. для вузов. - М.: ИНФРА-М, 2006. - 160 с.

17. Дрейпер Н., Смит Г. Прикладной регрессионный анализ. - М.: Вильямс, 2016. - 912 с.

18. Орлов А.И. Эконометрика: учеб. для вузов. - Ростов н/Д: Феникс, 2009. -576 с.

19. Кадочникова Е.И. Эконометрика: конспект лекций / Каз. федер. ун-т. Казань, 2013. - 106 с.

\section{References}

1. Mumladze R.G., Guzhina G.N. Ekonomika i sotsiologiia truda [Economics and sociology of labour]. Moscow, KNORUS, 2019, 320 p.

2. Iazenko E.I. Primenenie razlichnykh metodik $\mathrm{v}$ opredelenii optimal'noi chislennosti personala predpriiatiia [Utilization of different methods in definition of optimum companies personnel number]. Rossiiskoe predprinimatel'stvo, 2012, 
no. 17 , pp. 79-84, available at: https://elibrary.ru/item.asp?id=17897069 (accessed 04 May 2020).

3. Korshunova E.D. [et al.]. Ekonomika, organizatsiia i upravlenie promyshlennym predpriiatiem [Economics, organization and management of an industrial enterprise]. Moscow, KURS, INFRA-M, 2019, 272 p.

4. Pavlenko A.P. Opredelenie neobkhodimoi chislennosti personala organizatsii [Determination of necessary number of personnel in the company]. Normirovanie $i$ oplata truda $v$ promyshlennosti, 2016, no. 5, pp. 17-30.

5. Sharashkin A.N., Nikitina L.M. Razrabotka i obosnovanie metodiki opredeleniia optimal'noi chislennosti personala [Development and justification of a methodology for determining the optimal number of personnel]. Dizain. Materialy. Tekhnologiia, 2012, no. 4, pp. 136-141.

6. Balash O.S. Ekonometricheskoe modelirovanie prostranstvennykh vzaimodeistvii [Econometric modeling of spacial interaction]. Izvestiia Saratovskogo universiteta. Ekonomika. Upravlenie. Pravo, 2012, no. 3, pp. 30-35.

7. Balash O.S., Kharlamov A.V. Ekonometricheskoe modelirovanie prostranstvennykh dannykh [Econometric modeling of spatial data]. Saratov, Nauchnaia kniga, 2010, 112 p.

8. Baldin K.V. [et al.]. Ekonometrika [Econometrics]. Moscow, Dashkov i Ko, 2017, 564 p.

9. Temukueva Zh.Kh. Korreliatsionno-regressionnyi analiz kak indikator otbora pokazatelei pri provedenii faktornogo ekonomicheskogo analiza [Correlation and regression analysis as an indicator of selection indices during factorial]. Problemy sovremennoi nauki i obrazovaniia, 2016, no. 19, pp. 67-69.

10. Prozorova Iu.Iu., Khomiachenko A.A. Ispol'zovanie korreliatsionnoregressionnogo analiza $\mathrm{v}$ protsesse analiza effektivnosti ispol'zovaniia trudovykh resursov predpriiatiia [Using correlation and register analysis in the process of analysis of the efficiency of the use of the labor resources of the enterprise]. Tavricheskii nauchnyi obozrevatel', 2017, no. 20, pp. 32-35.

11. Baraz V.R. Korreliatsionno-regressionnyi analiz sviazi pokazatelei kommercheskoi deiatel'nosti s ispol'zovaniem programmy Excel [Correlation and regression analysis of the relationship between business indicators using Excel]. Yekaterinburg, Ural State Technical University, 2005, 102 p.

12. Krasil'nikov D.E. Algoritm vychisleniia koeffitsienta vyborochnoi determinatsii v MS-Excel [The algorithm of sample determination coefficient calculation in MS-Excel]. Trudy NGTU im. R.E. Alekseeva, 2016, available at: https://cyberleninka.ru/article/n/algoritm-vychisleniya-koeffitsienta-vyborochnoy-determinatsii-vms-excel (accessed 04 May 2020).

13. Companion to contemporary economic thought. Ed. Michael Bleaney, David Greenaway, Dr Ian Stewart (Russ. ed.: D. Grineuei [et al.]. Panorama ekonomicheskoi mysli kontsa XX stoletiia: v 2 t. St. Petersburg, vol. 2, 2002). 
14. Eliseeva I.I. [et al.]. Ekonometrika [Econometrics]. Moscow. Iurait, 2017, 449 p.

15. Andreeva N.V., Cherviakova M.Iu. Razrabotka metodiki prognozirovaniia $\mathrm{s}$ ispol'zovaniem korreliatsionno-regressionnogo analiza [Development of forecasting methods using correlation and regression analysis]. Ekonomicheskii analiz: teoriia i praktika, 2013, no. 37, pp. 38-45.

16. Kolemaev V.A. Ekonometrika [Econometrics]. Moscow, INFRA-M, 2006, 160 p.

17. Draper N., Smith H. Applied regression analysis (Russ. ed.: Dreiper N., Smit G. Prikladnoi regressionnyi analiz. Moscow, Vil'iams, 2016, 912 p.).

18. Orlov A.I. Ekonometrika [Econometrics]. Rostov-on-Don, Feniks, 2009, 576 p.

19. Kadochnikova E.I. Ekonometrika [Econometrics]. Kazan, Kazan Federal Unviersity, 2013, 106 p.

Оригинальность $87 \%$

Получено 26.05.2020 Принято 19.06.2020 Опубликовано 28.09.2020

\author{
E.E. Zhulanov, V.P. Postnikov, K.A. Shishkina
}

\title{
IMPROVING THE MECHANISM FOR REGULATING THE NUMBER OF PERSONNEL IN THE OIL REFINING ENTERPRISE BASED ON REGRESSION ANALYSIS METHODS
}

\begin{abstract}
The article offers an innovative approach to regulating the number of personnel of an oil-producing enterprise. Determining the optimal number of employees will reduce costs, which in conditions of instability has a positive effect on the efficiency of the enterprise as a whole. Existing methods for determining the number of employees, traditionally used by enterprises, do not take into account the impact of professional experience on labor costs. The new approach is based on econometric modeling, which allows one to identify a decrease or increase in the labor cost per operation, depending on the number of repetitions. Econometrically adjusted labor intensity standards permits flexible re-evaluation of changes in labor standards and determination of the amount of labor resources required by the enterprise to perform a specific amount of work. To confirm the hypothesis, an analysis was conducted for 10 similar works based on data for 12 months. Models were constructed that reflect the impact of professional skills on specific labor costs for jobs with the strongest connection between the parameter and the factor: participation in developing plans for inspections and preventive repairs of equipment, control of physical volumes performed by contractors of works on administrative and warehouse facilities, and generation of data about discrepancies between the quality of supporting materials and equipment and requirements of technical documentation and standards. Based on a comparison of the adjusted labor costs of regression modeling and the actual standards, it can be concluded that the use of an innovative approach clarifies the value of labor costs, which clarifies the number of employees required.
\end{abstract}

Keywords: staffing regulation, econometric modeling, regression approach, labor costs, labor standards. 
Evgeny E. Zhulanov - Doctor of Economics, Professor, Department of Economics and Industrial Management, Perm National Research Polytechnic University, e-mail: zeepstu@yandex.ru.

Vladimir P. Postnikov - Candidate of Economic Sciences, Associate Professor, Department of Economics and Industrial Management, Perm National Research Polytechnic University,e-mail: v.p.o.s.t.v@mail.ru.

Kseniya A. Shishkina - Master's Student, Department of Economics and Industrial Management, Perm National Research Polytechnic University, e-mail: shishckina.xenia2014@yandex.ru.

Received 26.05.2020 Accepted 19.06.2020 Published 28.09.2020 